\title{
REPENSANDO O DIREITO À SAÚDE E A RESPONSABILIDADE DO ESTADO À LUZ DA TEORIA DE JUSTIÇA DE JOHN RAWLS
}

\author{
Heloisa Sami Daou ${ }^{1}$ \\ José Claudio Monteiro de Brito Filho²
}

\section{RESUMO}

Artigo que problematiza acerca da responsabilidade do Estado na garantia do direito à saúde à luz da teoria de justiça de John Rawls. Analisa-se, inicialmente, o direito à saúde, sua caracterização e tratamento constitucional. Depois, trata-se da política pública do SUS, bem como de alguns argumentos que negam a garantia do direito à saúde nos moldes concebidos pelo Constituinte. Por fim, com base na teoria de justiça como equidade de John Rawls, delineada na obra Uma teoria da Justiça, suscita-se reflexão envolvendo a responsabilidade do Estado na garantia do direito fundamental social à saúde.

Palavras-Chave: Direito à saúde; Política Pública; Responsabilidade do Estado; Justiça como Equidade; John Rawls.

\section{RETHINKING THE RIGHT TO HEALTH AND THE RESPONSIBILITY OF THE STATE IN THE LIGHT OF JOHN RAWLS'S THEORY OF JUSTICE}

\begin{abstract}
Article that problematizes about the State's responsibility in guaranteeing the right to health in the light of John Rawls`s theory of justice. It's analyzed the right to health, its characterization and constitutional treatment. Then, it is be discuss the public policy of the SUS, as well as some arguments that deny the guarantee of the right to health along the lines thinked by the constituent. Finally, based on John Rawls's theory of justice as equity, outlined in A Theory of Justice, it is raised reflection involving the responsibility of the State in guaranteeing the fundamental social right to health.
\end{abstract}

Keywords: Right to health; Public Policy; Responsibility of the State; Justice as Fairness; John Rawls.

\footnotetext{
${ }^{1}$ Mestranda do programa de Pós-Graduação stricto sensu do Centro Universitário do Estado do Pará - CESUPA. E-mail: helo_daou@yahoo.com.br.

${ }^{2}$ Doutor em Direito das Relações Sociais pela PUC/SP. Professor dos Programas de Pós-Graduação em Direito da UFPA e do CESUPA. E-mail: jclaudiobritofilho@gmail.com.
} 


\section{INTRODUÇÃO}

Dentre os direitos sociais fundamentais previstos na Constituição da República Federativa do Brasil de 1988 (CRF/88), o direito à saúde, ou a falta dele, tem suscitado inúmeros debates na doutrina e na jurisprudência ${ }^{3}$.

Nesse sentido, a CRF/88 é paradigmática, pois reconheceu toda força e fundamentalidade aos direitos sociais. Portanto, a Carta Magna simboliza um marco jurídico de democracia e institucionalização dos direitos fundamentais no País, uma vez que o valor da dignidade da pessoa humana, como fundamento do Estado Democrático de Direito, sobre o qual se funda o Brasil, insculpido no art. $1^{\circ}$, III da CRF/88, impõe-se como núcleo básico de toda hermenêutica do sistema jurídico, como critério de valoração e baliza de atuação estatal.

$\mathrm{O}$ direito à saúde está disposto na CRF/88 no Título II, destinado aos direitos e garantias fundamentais, Capítulo II, que versa sobre os direitos sociais, ou seja, da ordem social, que tem como objetivo o bem-estar e a justiça social. $\mathrm{O}$ art. $6^{\circ}$ da CRF/88 estabelece como direitos sociais fundamentais a educação, a saúde, a alimentação, o trabalho, a moradia, o lazer, a segurança, a previdência social, a proteção à maternidade e à infância e a assistência aos desemparados.

Mais a frente, a partir do art. $196^{4}$, dentro do Título VIII, que trata da ordem social, especificamente na Seção II, tratando de saúde, o constituinte reconhece ser este um direito de todos e impõe ao Estado o dever de garantia, dando destaque às políticas sociais e econômicas que visem à redução do risco de doença e de outros agravos e ao acesso universal e igualitário às ações e serviços para sua promoção, proteção e recuperação.

Não obstante o mandamento constitucional, na prática, o que se observa é que a efetivação do direito à saúde ainda encontra óbice, tanto pela ineficácia do Estado na realização de políticas públicas para sua garantia quanto em razão de ainda existir resistência por parte da doutrina à plena e incondicional realização desse direito, a partir da força de algumas teorias que negam ao indivíduo o pleno gozo do direito à saúde, sustentadas em diversos argumentos, alguns dos quais serão aqui expostos.

Desse modo, o presente artigo objetiva repensar $\mathrm{o}$ direito à saúde $\mathrm{e}$ a responsabilidade do Estado na sua garantia à luz da teoria de justiça de John Rawls, chamada de teoria da justiça como equidade. Para tanto, este ensaio está divido em três partes.

Inicialmente, a intenção é explorar o direito à saúde no que diz respeito às suas características e tratamento constitucional.

Depois, analisar-se-á a política pública do SUS, forma de garantia do direito à saúde no ordenamento jurídico brasileiro, tal como o legislador determina, bem assim serão apresentados alguns argumentos que, levados a efeito, acabam por negar ao indivíduo o direito à saúde.

\footnotetext{
${ }^{3}$ Exemplo disso é a celeuma pendente de julgamento no Supremo Tribunal Federal relacionada à possibilidade do fornecimento, pelo Estado, de medicamentos de alto custo, bem como à possibilidade de provocação do judiciário em situações que envolvam concessão de medicamentos sem registro na Agência Nacional de Vigilância Sanitária (ANVISA). Quando demandas como estas chegam ao Órgão Supremo do Poder Judiciário do País e ganham repercussão geral, como aconteceu recentemente nos Recursos extraordinários (REs.) 566471 e 657718, é sinal de que há uma falha na prestação de saúde pelo Poder Público, situação que faz crescer o número de ações judiciais.

${ }^{4}$ Art. 196. A saúde é direito de todos e dever do Estado, garantido mediante políticas sociais e econômicas que visem à redução do risco de doença e de outros agravos e ao acesso universal e igualitário às ações e serviços para sua promoção, proteção e recuperação.
} 
E, por fim, no último tópico, com base na teoria de justiça como equidade de John Rawls, delineada na obra Uma teoria da Justiça (2016), será suscitada reflexão envolvendo a responsabilidade do Estado na garantia do direito à saúde, no sentido de defender atuação necessária e indispensável na garantia dos direitos fundamentais sociais, considerados essenciais para sobrevivência digna.

O objetivo pretendido será alcançado por meio da análise do material doutrinário e legislativo referente ao tema, bem como se buscará suporte teórico necessário na Filosofia Política, especificamente na teoria rawlsiana de justiça como equidade.

Passa-se, então, a caracterização do direito à saúde no ordenamento jurídico brasileiro:

\section{O DIREITO À SAÚDE NO ORDENAMENTO JURÍDICO BRASILEIRO}

No início do século XIX, o mercado possuía relevância fundamental e a lógica da economia prezava pela não intervenção do Estado, buscando harmonizar o lucro privado e o bem público. O bem comum deveria ser alcançado pelo esforço de cada indivíduo em melhorar suas próprias condições.

Bastos (2007, p. 30), destaca que "a acumulação e distribuição mais justa e rápida da riqueza poderia ser obtida pelo simples processo de deixar as pessoas agirem por si...sem restrições da parte do Estado ou da opinião pública", em uma manifestação clara da doutrina do laissez-faire laissez passer, n'est pas trop de gouverner.

Portanto, as Constituições que nasceram no século XVIII e XIX tiveram a missão de estruturar esse Estado Liberal. O Direito legitima o discurso de proteção aos direitos de primeira geração, limitados às liberdades básicas de matriz liberal-burguesa, relacionados com a vida, a igualdade formal, a propriedade, a liberdade e a segurança. Nesse contexto, foi dado especial destaque aos direitos civis e políticos como as liberdades de expressão e consciência, culto, associação, imprensa, entre outras liberdades básicas e era "impensável qualquer função do Estado de cunho paternalista que pudesse colocar em risco este equilíbrio natural das forças, esta igualdade formal” (BASTOS, 2007, p. 32).

Porém, constantes reinvindicações dos movimentos populares que buscavam por garantia de maiores direitos levam à crise do Estado liberal, tornava-se impossível conter os já por demais contidos movimentos de socialização do capital. Emerge, assim, uma nova forma de Estado, o Estado Social, que deixa de ser somente um mero government by law e transforma-se em um government by policies, na medida em que toma para si em forma de metas ou programas de ação a preocupação social e não apenas econômica.

"A garantia dos direitos individuais clássicos tornou-se insuficiente, na medida em que o Estado deixou de ser o único opressor" (BARCELLOS, 2011, p.136). Ou seja, a dinâmica do livre mercado, dentre outros fatores, fazia crescer as desigualdades sociais, surgindo a necessidade da afirmação de outros direitos básicos, aqueles de cunho econômico e social, em outras palavras, os direitos de segunda geração. Isso porque não bastava que todos fossem livres apenas formalmente, se na realidade, não o eram, pois não possuíam condições de liberdade material.

Bastos (2007, p. 41), destaca que o Constitucionalismo Social nasce a partir do reconhecimento de que "o Estado Social, por mudar a substância, mas não a forma, que permanece com Estado de Direito, continua acreditando no direito como a base da organização social, e não a Economia, embasada em atos e resultados". Surgem, então, os direitos sociais, também vinculados à ideia de igualdade material. 
A CRF/88 legitima o Estado Social e Democrático de Direito (art. $1^{\circ}$ ) e traz um catálogo de direitos sociais (art. $6^{\circ}$ ), todos inseridos no rol dos direitos fundamentais (art. $5^{\circ}$ a 17). A formação desse catálogo de direitos fundamentais é, portanto, fruto da luta de grupos sociais que almejaram, em cada momento da história da sociedade, o reconhecimento e a garantia de suas necessidades fundamentais. É assim que o direito à saúde, como direito social, é fruto de anos de luta.

Importante destacar que, nos dias atuais, o entendimento majoritário é no sentido de que não há diferença substancial entre os direitos civis e políticos e os direitos econômicos, pois todos exigem uma conduta do Estado, comissiva ou omissiva, em menor ou maior grau.

Todos os direitos fundamentais são essenciais. A bem da verdade "os Direitos Humanos, todos, são complementares entre si, e interdependentes" (BRITO FILHO, 2015, p. 35). E, mais ainda, a garantia de todos e de cada um é necessária para promoção da dignidade da pessoa humana, pois eles fazem parte de um conjunto essencial para a existência em condições de dignidade.

A partir do art. 196, após estabelecer a saúde como direito fundamental, o constituinte destaca a forma pela qual a saúde deve ser garantida, dando destaque às políticas sociais e econômicas, com vistas à garantia da saúde, direito de todos e dever do Estado.

Importante destacar que o conceito de saúde evoluiu, hoje não mais é considerada somente como ausência de doença. A Organização Mundial de Saúde - OMS, no preâmbulo de sua Constituição de 1946 define que "A saúde é um estado de completo bem-estar físico, mental e social, e não consiste apenas na ausência de doença ou de enfermidade." (ORGANIZAÇÃO MUNDIAL DA SAÚDE, 1946, não paginado).

Este conceito foi utilizado por muitos anos e vem sendo expandido para incorporar as dimensões física, emocional, mental, social e espiritual do homem. Atualmente, compreendese que a saúde não é um fenômeno isolado, mas o resultado da interação de todas as condições em que vive a população, como argumenta Pereira (2014, p. 65):

Não se pode considerar o indivíduo fora de sua realidade, econômica, social e ambiental. O clima, o tipo de moradia, a qualidade da água consumida, a possibilidade dos tratamentos dos dejetos domésticos, o ar que se respira, a degradação social ou a desnutrição, estilos de vida pessoais e formas de inserção de diferentes parcelas da população no mundo do trabalho. A saúde é produto e parte do estilo de vida, das condições de existência e do equilíbrio das diversas dimensões do homem.

Sendo, então, a saúde resultante de diferentes dimensões, para se chegar ao seu melhor conceito, imprescindível observar o ser humano como um todo, suas condições de vida, de habitação, de trabalho e de acesso aos serviços de saúde. Trata-se, portanto, de um alargamento conceitual e, somente a partir dele se podem pensar boas políticas públicas, direcionadas a garantir a saúde dos indivíduos, entendendo que, muitas vezes, alcançar este estado exigirá melhorar a qualidade e condições de vida da população. Isso porque:

A incorporação à base jurídico-legal do SUS de uma concepção ampliada de saúde que inclui os condicionantes econômicos, sociais, culturais e bioecológicos e uma visão abrangente e integrada das ações e serviços de saúde, busca superar a visão dominante de enfocar a saúde pela doença, sobretudo nas dimensões biológica e individual. Sem negar o peso e a importância das doenças na configuração de sistemas de saúde e na consequente oferta de ações (VASCONCELOS; PASCHE, 2012, p. 532). 
No mesmo sentido, ao tratar da equidade na saúde, Sen (2000, p. 74), acrescenta:

Equidade na saúde não pode se preocupar somente com a saúde, isoladamente. (...). Equidade na saúde com certeza não se refere apenas ao acesso à saúde, muito menos ao enfoque ainda mais restrito do acesso aos serviços de saúde. Na verdade, equidade na saúde como conceito tem um alcance e uma relevância extremamente amplos.

Assim, o conceito de saúde engloba a própria noção de justiça, pois qualquer teoria de justiça social que busque uma distribuição de bens e riquezas na sociedade de forma equitativa, preocupada em dar ao ser humano condições de desenvolver suas capacidades, precisa lembrar sempre da importância da saúde para que o crescimento individual e social seja possível.

Por isso, em busca de uma melhor abordagem para políticas de saúde deve-se levar em conta uma série de fatores ligados ao indivíduo singularmente considerado, ou seja, que não são apenas sociais e econômicos, mas também uma variedade de outros parâmetros, "como deficiências pessoais, predisposições individuais e doenças, riscos epistemológicos de regiões especificas, influência de variações climáticas etc.” (SEN, 2000, p. 86).

A saúde, conforme previsão constitucional deve ser garantida por meio de política pública com a implantação do Sistema Único de Saúde - SUS e suas diversas formas de atuação. tópico.

Sobre o SUS e a garantia do direito à saúde, far-se-á aprofundamento no próximo

\section{A GARANTIA DO DIREITO À SAÚDE}

Após a caracterização do direito à saúde e delimitação do tratamento constitucional que recebe do legislador, é preciso compreender a política pública do SUS como forma de garantia desse direito, apontando suas fragilidades, bem como conhecer argumentos que, levados a efeito, acabam por negar ao indivíduo o direito a saúde e, em consequência, o direito de viver em condições que lhe proporcionem a realização do seu plano de vida.

O tema políticas públicas vem ganhando crescente destaque desde o final do século passado e começo do presente. No Brasil, o tema possui crescente importância por muitos motivos, dentre os quais está o fato de que não basta a CRF/88 prever uma enorme gama de direitos sociais sem que se compreenda como os Poderes Públicos e os órgãos do Estado devem atuar para concretizar, na prática, esses direitos.

As políticas públicas são arranjos complexos, típicos da atividade políticoadministrativa. Referem-se a institutos diversos com incidências em várias áreas do conhecimento e atuação humana, por isso também o direito deve conhecer e descrever, pois elas norteiam toda a atividade do Estado para consecução dos direitos dos indivíduos.

Nesse sentido, importante conceito de políticas públicas é o de Dworkin (2002, p.

Denomino "política" aquele tipo de padrão que estabelece um objetivo a ser alcançado, em geral uma melhoria em algum aspecto econômico, político ou social da comunidade (ainda que certos objetivos sejam negativos pelo fato 
de estipularem que algum estado atual deva ser protegido contra mudanças adversas).

Esse conceito traz em si uma importância fundamental, pois, segundo destaca Smanio (2013, p. 5), “(...) ainda nos EUA, coube a Ronald Dworkin, no final da década de 1970, o entendimento de que o tema Políticas Públicas também deveria caber na Teoria Geral do Direito".

Ainda sobre a conceituação de políticas públicas, destaca-se Bucci (2006, p. 39), quem melhor resume, nos seguintes termos:

Programas de ação governamental que resulta de um processo ou conjunto de processos juridicamente regulados - processo eleitoral, processo de planejamento, processo de governo, processo orçamentário, processo legislativo, processo administrativo, processo judicial - visando coordenar os meios à disposição do Estado e as atividades privadas, para a realização de objetivos socialmente relevantes e politicamente determinados.

Desse modo, as políticas públicas sociais de responsabilidade, especialmente dos Poderes Legislativo e Executivo, são a via primeira de materialização dos direitos sociais fundamentais e normas constitucionais definidoras de tais direitos e são, ainda, mais do que simples programas de governo, verdadeiras normas jurídicas, dotadas, assim, de imperatividade, ou seja, de capacidade para impor algo ao seu destinatário. Por isso, "não há como não fixarmos um conceito jurídico de políticas públicas, pois estas são também fenômeno jurídico, que pode ser realizado, executado, controlado, enfim efetivado juridicamente" (SMANIO, 2013, p. 10).

No Brasil o SUS é a politica publica escolhida pelo legislador que deve ser executada pelo Estado para garantia do direito à saúde. É regido, basicamente, pela Lei no ${ }^{\circ}$. 8.080/1990 e Lei ${ }^{\circ}$. 8.142/1990, além da CRF/88. A primeira dispõe sobre as condições, a organização das ações e o funcionamento dos serviços, versando sobre a promoção, proteção e recuperação da saúde. A segunda dispõe sobre a participação democrática no Sistema, bem como sobre as transferências intergovernamentais de recursos financeiros na área da saúde.

Sobre os princípios reguladores do SUS, Prata (2013, p. 254) sintetiza:

Os princípios do sistema de proteção à saúde, instituídos pelo art. 196 da Constituição e art. $2^{\circ}, \S 1^{\circ}$, da LOS são a universalidade, a igualdade e a gratuidade no acesso ao sistema do SUS.

$\mathrm{O}$ principio da universalidade tem por objetivo os titulares do direito à saúde, outorgando a garantia de que toda e qualquer pessoa, no território brasileiro, possa ter acesso gratuito aos serviços de saúde oferecidos pela rede pública de atendimento. (...).

O princípio da igualdade garante aos usuários do sistema as mesmas oportunidades de acesso aos serviços de saúde, sem distinções, preconceitos ou privilégios.

(...)

O princípio da integralidade, por sua vez, é previsto no inciso II do art. 198 da Constituição e fixa como uma das diretrizes do sistema de saúde pública a totalidade de abrangência de atendimento, em todos os níveis de complexidade, sintetizando desta forma os princípios da universalidade e igualdade. 
Importante ressaltar, que a própria constituição, arts. 193, 194, 195 e 198 estabelece que o SUS deve ser custeado pela seguridade social, financiado por toda a sociedade por meio de tributos, o que evidencia seu caráter contributivo, bem como mediante recursos provenientes dos orçamentos da União, dos Estados, do Distrito Federal e dos Municípios. A iniciativa privada poderá participar do SUS em caráter complementar.

A Constituição prevê, ainda, no seu art. 23, II, a competência comum da União, Estados, Distrito Federal e Municípios para cuidar da saúde, embora, norteada pelo princípio da eficiência próprio da administração pública, a Lei $n^{\circ}$ 8.080/90 defina o que cabe a cada um dos entes federativos na matéria. Assim, a competência para questões relacionadas ao direito à saúde é solidária.

Contudo, ainda que a teoria do SUS seja estruturada para garantia de acesso universal, igualitário e integral, conforme apresentada acima, a prática revela a ótica utilitarista dos governantes, o que pode ser confirmado em vários aspectos. Primeiro, porque pensam à saúde a partir da coletividade, quando elaboram políticas com base nas necessidades da maioria das pessoas, como acontece na elaboração da lista de medicamentos essenciais, por exemplo, quando é óbvio que, na prática, as pessoas vão manifestar necessidades diferentes. Depois, porque o tratamento universal acaba se restringindo às tecnologias oferecidas pelo SUS, o que torna a integralidade uma utopia.

Em relação ao utilitarismo, ensina Vita (2007, p. 18) que:

O utilitarismo é uma doutrina ética teleológica por dar primazia a uma visão do bem humano - concebido em termos da máxima satisfação possível de desejos e aspirações individuais - sobre princípios de justiça e do direito. Estes são, em uma ética teleológica, instrumentais àquela visão: que princípios devem ser implementados pelas instituições sociais básicas depende de considerações agregativas sobre o total líquido de satisfação de preferências e desejos individuais que pode ser alcançado.

Kymlicka (2006, p. 11) acrescenta que, o utilitarismo "afirma que o ato ou procedimento moralmente correto é aquele que produz a maior felicidade para os membros da sociedade". Mais adiante, acrescenta que, no utilitarismo, as preferências dos indivíduos não são satisfeitas quando contrárias ao que "maximiza a utilidade de maneira geral" (KYMLICKA, 2006, p. 25).

Assim, resta evidente a razão de se afirmar que a política do SUS revela a ótica utilitarista do governo, em face de algumas características da teoria: a predominância do bem sobre o justo, com consideração do resultado para indicação do ato moralmente correto, assim como porque o utilitarismo permite que as preferências dos membros dos grupos minoritários sejam preteridas, desde que com isso se maximize a utilidade e se contemple a maior parte dos indivíduos.

Embora se referindo à educação, a afirmação de Brito Filho (2014, p. 177) pode ser aplicada à saúde nos mesmos termos:

É o que acontece, por exemplo, quando um governo afirma, normalmente de forma triunfante, que a medida que vai adotar possibilitará, por exemplo, que 90\% das crianças tenham educação básica. Aparentemente tem-se aqui uma boa medida, pois a maioria das crianças será alfabetizada. O problema é que, na verdade, o que se está a dizer é que, por causa da medida adotada para cumprir uma obrigação essencial do Estado, $10 \%$ de todas as crianças serão 
excluídas do direito de ter educação formal, normalmente as mais necessitadas.

Dessa forma, ainda que o constituinte tenha relacionado o direito à saúde a coletividade é preciso ter clareza de que isso em nada diminui seu conteúdo e nem a obrigatoriedade de sua realização com base nas necessidades de cada pessoa individualmente considerada, isso porque a promoção da dignidade da pessoa humana é assegurada por meio dos direitos e garantias fundamentais, o que desloca a matéria da esfera política para o âmbito do Direito, transformando em uma obrigação jurídica. Entender diferente é reforçar a tese reducionista daqueles que se utilizam do fato de ser o direito à saúde um direito social para lhe negar o caráter de direito subjetivo de índole individual, negando também que possa ser pleiteado judicialmente na via individual.

Nesse sentido reducionista, manifesta-se Scaff (2010, p. 30):

É nítido que este preceito determina um direito à saúde através de "políticas sociais e econômicas", porém a interpretação que vem sendo dada a este preceito é a de que este é um direito individual, que pode ser gozado diretamente por cada indivíduo, e não através da implementação de uma política pública. Aprisiona-se o interesse social e concede-se realce ao direito individual.

Contudo, em face da caracterização constitucional do direito à saúde, não é possível interpretar no mesmo sentido do autor. Ao contrário, é dizer: se percebida, na prática, que a realização dos direitos fundamentais por meio de políticas públicas voltadas à coletividade não é satisfatória para um indivíduo que seja, está este indivíduo autorizado a requerer frente aos poderes públicos medidas que lhe garantam efetividade da prestação de direitos fundamentais pelo Estado, pois a sua dignidade de pessoa humana é razão suficiente para isso. Nesse sentido:

(...) é forçoso admitir que o direito à saúde, embora classificado como um direito social, também é um direito fundamental individual, pelo menos em sua fruição, com a consequência de que o Estado é obrigado a proporcionar a cada indivíduo o que for necessário para que esse direito seja satisfeito (BRITO FILHO, 2014, p. 227-246).

É evidente que a questão da saúde envolve, além da coletividade, o indivíduo em sua particularidade. O direito fundamental à saúde, embora previsto no rol dos direitos sociais, pode também ser tutelado na esfera individual, pois sua fruição se dá no plano do indivíduo.

O Estado deve planejar e executar políticas públicas e serviços públicos que garantam saúde das pessoas, mas deve também garantir o direito à saúde de cada pessoa individualmente. Em outras palavras: o Estado deve assegurar saúde à coletividade, mas não pode se escusar de nenhum indivíduo, porque ao lado do interesse geral há o interesse pessoal e as pessoas vão manifestar necessidades diferentes. "Cuida-se, portanto, de direito de todos e de cada um, de tal sorte que o desafio é saber harmonizar, sem que ocorra a supressão de uma das dimensões, ambas as perspectivas." (SARLET, 2011, p. 144).

Nesse aspecto, facilmente poderá ser suscitado outro argumento contrário a efetivação do direito à saúde, a falácia de que os recursos materiais são finitos e que os direitos sociais requerem maiores custos para sua garantia, ou seja, diante das necessidades sociais infinitas "há um limite de possibilidades materiais para esses direitos" (BARCELLOS, 
2011, p. 277). Isso levaria à possibilidade de os direitos sociais serem realizados na medida da disponibilidade de recursos, ou seja, na reserva do possível.

Neste sentido, mesmo autor acima citado afirma:

Ocorre que os recursos são escassos e as necessidades infinitas. Como o sistema financeiro é um sistema de vasos comunicantes, para se gastar de um lado precisa-se retirar dinheiro de outro. Assim, seguramente, mais verbas para o ensino fundamental pode implicar em menos verbas para o ensino superior; e a mesma disputa financeira pode ocorrer no custeio da saúde pública. Nestes casos, a discricionariedade do legislador está presente (SCAFF, 2010, p. 29).

Esse argumento da reserva do possível ganhou corpo no Brasil, especialmente utilizado pelo Estado para justificar a não realização dos direitos sociais. $\mathrm{O}$ argumento traz um conceito econômico para a discussão jurídica e transfere para a esfera da disponibilidade daquele responsável pela destinação dos recursos orçamentários a garantia de direitos sociais, o que pretere o próprio mandamento constitucional, privilegiando aspectos meramente econômicos.

Em verdade esse argumento não se sustenta. Primeiro porque o orçamento e a sua destinação estão nas mãos dos administradores; depois porque o Estado é organizador e alocador de recursos e, ao mesmo tempo, responsável por arrecadá-los. Logo, governar é a arte de escolher prioridades e avaliar bem as necessidades.

Nesse sentido, é a própria sociedade quem suporta os custos dos direitos por meio da tributação. Depois, tal como sustentaram Sunstein e Holmes, na célebre obra $O$ custo dos direitos, todos os direitos têm um custo:

\begin{abstract}
A la verdade evidente de que los derechos dependen de los gobiernos es preciso agregar um corolário lógico, rico en implicaciones: los derechos cuestan dinero. Es imposible protegerlos o exigirlos sin fondos y apoio públicos. Esto es tan certo para los derechos antigos como para los nuevos, para los de los estadounidenses antes del New Deal de Flanklin Delano Roosevelt como después. Tanto el derecho al bienestar como a la propriead privada tienem costos públicos. El derecho a la libertad de contratar supone costos, no menos que la atención médica, el derecho a la libertad de expresión o a uma vivenda decente. Todos los derechos reciben algo del tesoro público (SUNSTEIN, HOLMES, 2011, p. 33).
\end{abstract}

Na visão de Sunstein e Holmes (2011, p 37), os indivíduos que não vivem sob a tutela de governos capazes de cobrar impostos e encontrar soluções efetivas não têm direitos jurídicos. A ausência de Estado significa ausência de direitos. Para eles, "um derecho sólo existe si y cuando tiene costos presupuestarios" (SUNSTEIN; HOLMES, 2011, p. 38).

Logo, o que se pode perceber é que não são os recursos que são finitos, mas as escolhas de prioridades daqueles responsáveis pela destinação dos recursos financeiros que não estão obedecendo ao mandamento do legislador e as próprias prioridades dos indivíduos destinatários da norma constitucional, pois é certo que os direitos sociais, bem assim o direito à saúde, são todos essenciais para a vida digna.

Desse modo, a normas constitucionais que definem o rol de direitos fundamentais são normas jurídicas dotadas de imperatividade, o que significa dizer que os Poderes Legislativo, Executivo e Judiciário lhe devem fiel cumprimento, pois esses direitos são as 
ferramentas oferecidas ao Estado pelo constituinte para que "preste as devidas homenagens ao princípio eleito como a razão de ser da própria existência do Estado, qual seja, o principio da dignidade da pessoa humana" (PAES, 2015, p. 113).

Por essa razão, Sarlet (2015, pg. 67) afirma que os direitos fundamentais são "parâmetros hermenêuticos e valores superiores a toda a ordem constitucional e jurídica". E, acrescenta:

Direitos fundamentais são (...) todas aquelas posições jurídicas concernentes às pessoas, que, do ponto de vista do direito constitucional positivo, foram, por seu conteúdo e importância (fundamentalidade em sentido material), integradas ao texto da constituição e, portanto, retiradas da esfera da disponibilidade dos poderes constituídos (fundamentalidade formal), bem como as que, por seu conteúdo e significado, possam lhes ser equiparados, agregando-se à Constituição material, tendo, ou não, assento na Constituição formal (aqui considerada a abertura material do Catálogo) (SARLET, 2015, p. 78).

Desse modo, os direitos sociais fundamentais possuem uma tríplice característica: o Estado está obrigado a proporcioná-los aos indivíduos, ou a todos eles; sem eles não há condições de vida digna e, ainda, eles são direitos essenciais para todas as pessoas. "Os direitos sociais encontram seu fundamento e sua função na proteção das pessoas no contexto de sua situação concreta na sociedade." (SARLET, 2011, p. 131).

E ainda:

O Estado assume a tarefa de proporcionar prestações necessárias e serviços públicos adequados para o pleno desenvolvimento da personalidade humana, por meio da realização de fins materiais. Para cumprir os ideais de Estado Social, a ação dos governantes deve ser racional e planejada, o que ocorre por meio da elaboração e implementação de políticas públicas.

As políticas públicas, definidas como programas de ação governamental voltados à concretização dos direitos fundamentais, envolvem a atividade de planejamento, (...) (DUARTE, 2013, p. 16-17).

O Estado deve ter atuação decisiva na formulação das políticas públicas voltadas para realização de direitos fundamentais, diminuição de desigualdade na aquisição de serviços públicos a partir do planejamento, com a utilização de instrumentos de participação social fomentando o debate sobre os assuntos relevantes para a população. E, após isso, deve atuar na execução dessas medidas com vistas à eficiência e adequação, além de trabalhar sempre com a transparência de modo que os cidadãos possam controlar o alcance dos objetivos e metas almejados.

Em sentido amplo, o direito à saúde abrange a consecução de medidas para salvaguarda do direito e da própria saúde dos indivíduos, bem como a organização de instituições, serviços, ações e procedimentos. Em sentido estrito, a dimensão prestacional traduz-se no fornecimento de bens materiais ao titular desse direito fundamental (SARLET; FIGUEIREDO, 2008).

O Estado não outorga saúde à população, mas cria uma estrutura que mantém um sistema público de saúde visando dar efetividade ao texto Constitucional. É nesse sentido que o SUS deve ser concebido e executado, pois só assim é possível concretizar a Constituição. 


\section{REPENSANDO O PAPEL DO ESTADO NA GARANTIA DO DIREITO À SAÚDE À LUZ DA TEORIA DE JUSTIÇA DE JOHN RAWLS}

Nos tópicos anteriores, o objetivo principal foi esclarecer acerca das características do direito à saúde e sua garantia por meio do SUS, bem como se buscou rechaçar qualquer argumento restritivo desse direito.

No presente tópico, apresentar-se-á a teoria de justiça de John Rawls como base teórica adequada e suficiente para fundamentar todo o exposto nos tópicos anteriores.

Os argumentos contra ou em favor do direito à saúde são, muitas vezes, apresentados sem que se indique claramente uma concepção de justiça como sustentáculo. Porém, em relação a essas concepções:

Identificá-las permite entender porque algo que parece óbvio: o dever do Estado de oferecer o básico aos indivíduos, que no caso aqui discutido é a saúde plena, pode ser singelamente negado por diversos autores, como se fosse algo normal (BRITO FILHO; FERREIRA, 2015, p. 284).

John Rawls inaugurou uma nova forma de se conceberem os deveres e o papel do Estado para com a sociedade. Ele valoriza o indivíduo, todos os indivíduos, fixando a ideia de que o Estado tem por função, além do respeito pelas liberdades, a satisfação das necessidades básicas das pessoas para as quais governa, não podendo descuidar de nenhuma. Para ele, "tratar casos semelhantes de maneira semelhante não é garantia suficiente de justiça substantiva" (RAWLS, 2016, p.71).

Assim, esta é uma primeira justificativa para a escolha da teoria de Rawls, que, inclusive, apresenta-se como uma alternativa para o utilitarismo, no sentido de, primordialmente, levar em consideração o indivíduo, pois para Rawls $(2016$, p. 4) "Cada pessoa possui uma inviolabilidade fundada na justiça que nem o bem-estar de toda a sociedade pode desconsiderar".

Desse modo, a adequada concretização de direitos fundamentais, na visão rawlsiana deve, antes de qualquer coisa, estar voltada para as necessidades de cada pessoa, ou seja, não se admite que uma pessoa sequer seja sacrificada em suas necessidades básicas, nem mesmo em prol de um benefício para a coletividade.

Outro importante traço da teoria de Rawls é que ela mantém o respeito pela autonomia individual, mas considera que o Estado não pode se escusar de garantir a todos os indivíduos e a estes isoladamente uma gama de bens primários, bens necessários à consecução de qualquer projeto de vida. A atuação do Estado, assim, com base em uma ideia de justiça, se inicia e se esgota na distribuição de bens fundamentais, a partir daí o Estado deve ser neutro.

Bens básicos, na teoria de Rawls, são aqueles bens sociais que todos escolheriam sem conhecimentos importantes sobre suas próprias vidas e seu futuro, escolhidos antes mesmo da deliberação sobre os princípios de justiça, onde os indivíduos levam em conta apenas fatores gerais e não contingenciais.

Em suma, os bens primários na teoria de Rawls são definidos como coisas que sempre seria melhor ter mais do que menos, aquelas que todo homem racional deseja mais que outras ou deseja ainda que deseje outras. Desse modo:

o autor enumera os bens primários em uma lista preliminar (ele mesmo admite que ela possa ser aumentada), a qual contém os seguintes itens:

a) os direitos e liberdades fundamentais, que também constituem uma lista; 
b) liberdade de movimento e livre escolha de ocupação num contexto de oportunidades diversificadas;

c) poderes e prerrogativas de cargos e posições de responsabilidade nas instituições políticas e econômicas da estrutura básica;

d) renda e riqueza;

e) as bases sociais do auto-respeito (DIAS, 2007, pg. 67).

É possível resumir a lista de Rawls falando de autoestima ou autorrespeito, direitos, liberdade e oportunidades, bem como renda e riqueza (Rawls, 2016, p. 110). Mesmo numa teoria deontológica não é possível prescindir desses bens.

Com uma quantidade maior de bens primários Rawls conclui que “(...), em geral é possível prever um maior êxito na realização das próprias intenções e na promoção dos próprios objetivos, sejam quais forem esses objetivos." (RAWLS, 2016, p. 110). Em outras palavras: as pessoas, normalmente, podem ter maior certeza do sucesso dos seus planos de vida, quaisquer que sejam eles.

A sociedade de Rawls é presumidamente bem ordenada e ele denomina a situação inicial de posição original, onde as pessoas fazem eleição dos princípios da justiça. Nesse sentido, os dois princípios de justiça são formulados da seguinte maneira:

\footnotetext{
Primeiro princípio

Cada pessoa deve ter um direito igual ao mais abrangente sistema total de liberdades básicas iguais que seja compatível com um sistema similar de liberdades para todos.

Segundo princípio

As desigualdades econômicas e sociais devem ser dispostas de modo a que tanto:

(a) se estabeleçam para o máximo benefício possível dos menos favorecidos que seja compatível com as restrições do princípio de poupança justa, como (b) estejam vinculadas a cargos e posições abertos a todos em condições de igualdade equitativa de oportunidades (RAWLS, 2016, p. 376).
}

O primeiro princípio garante que todos devem ter as mesmas liberdades e o segundo, dividido em dois, garante igualdade de oportunidades e que renda e riqueza devem ser distribuídas, sempre pensando nos menos favorecidos. Rawls está preocupado que ninguém fique sem o que é básico e tudo isto é visto sob a perspectiva do indivíduo, sendo esta mais uma característica que justifica a eleição da teoria.

Cada pessoa tem seu plano racional de vida e a escolha dos princípios da justiça é orientada para que dela resulte a "melhor maneira de cada pessoa garantir seus objetivos, à luz das opções disponíveis" (RAWLS, 2016, p.144).

Acredita-se, assim, que toda produção de Rawls está diretamente relacionada à garantia de direitos sociais. Isso porque, para o autor, alguma distribuição de bem é devida "a todos os seres humanos, em virtude apenas de serem humanos" (FLEISCHACKER, 2006, p. 12). Depois porque os direitos sociais são todos necessários para uma vida digna, enquadramse no conceito de bens básicos. E, por fim, porque a distribuição desses bens cabe ao Estado.

É, com base nisso, que Fleischacker, mais a frente (2006, p. 12) sintetiza o conceito moderno de justiça distributiva nos seguintes termos:

Em resumo, dado o significado geral de "justiça", pelo menos as seguintes premissas são necessárias para se chegar ao conceito moderno de justiça distributiva: 
1. Cada indivíduo, e não somente sociedades ou a espécie humana como um todo, tem um bem que merece respeito, e aos indivíduos são devidos certos direitos e proteções com vistas à busca daquele bem;

2. Alguma parcela de bens materiais faz parte do que é devido a cada indivíduo, parte dos direitos e proteções que todos merecem;

3. O fato de que cada indivíduo mereça isso pode ser justificado racionalmente, em termos puramente seculares;

4. A distribuição dessa parcela de bens é praticável: tentar conscientemente realizar essa tarefa não é um projeto absurdo nem é algo que, como ocorreria caso se tentasse tornar a amizade algo compulsório, solaparia o próprio objetivo que se tenta alcançar; e

5. Compete ao Estado, e não somente a indivíduos ou organizações privadas, garantir que tal distribuição seja realizada.

As premissas acima podem ser resumidas em três: Em primeiro lugar, cada indivíduo é detentor de direitos básicos que lhe devem ser garantidos considerando suas necessidades individuais. Depois, dentre os direitos que devem ser distribuídos há uma parcela de bens materiais e, por fim, essa distribuição cabe ao Estado.

O direito à saúde, considerado como um bem básico a partir da teoria de Rawls é, assim, de responsabilidade do Estado e deve ser garantido a cada indivíduo a partir de suas necessidades, assim como a todos por meio de políticas públicas voltadas à coletividade.

Logo, é urgente que se rejeite qualquer teoria restritiva do direito à saúde, nos seguintes termos:

Para isso, a solução é dizer não à desigualdade, rejeitando-se teorias conservadoras e que só privilegiam quem já tem, subordinando o papel do Estado aos interesses dos governantes, e contra a sociedade, especialmente os menos favorecidos, sendo exemplos as teorias da reserva do possível; dos custos dos direitos; da prevalência da lei orçamentária; entre outras. E os abusos que, infelizmente, em certos casos são cometidos, e que acabam servindo de mote para justificar a retirado do mínimo das pessoas? Que sejam coibidos, mas sempre sendo tratados como exceções, pois a regra de toda e qualquer comunidade deve ser a de ter respeito por cada um de seus integrantes. É o que se convencionou chamar de igual consideração, e que, pensamos, é materializada, dentro das concepções mais importantes de justiça, no liberalismo de princípios, especialmente na teoria da justiça como equidade, de John Rawls (BRITO FILHO; FERREIRA, 2015, p. 288).

Desse modo, por estar toda produção científica de Rawls diretamente ligada à dignidade da pessoa humana e, por todos os motivos elencados é que ela é aplicável à realidade brasileira de garantia de direitos sociais, especialmente do direito à saúde.

\section{CONSIDERAÇÕES FINAIS}

Nos termos do que foi explanado no presente artigo, conclui-se que o princípio da dignidade da pessoa humana é imposto pelo constituinte como baliza de toda atuação Estatal e impõe que o direito à saúde seja garantido amplamente. 
Nesse sentido, é a CRF/88 paradigmática e as normas que instituem direitos fundamentais são dotadas de imperatividade, o que significa dizer que o Estado lhe deve fiel cumprimento, de modo a garantir aos indivíduos uma vida digna.

Há, contudo, duas questões frequentemente enfrentadas em relação à garantia de direitos sociais, especialmente do direito à saúde: a ineficiência das políticas públicas voltadas à coletividade e a força de argumentos que tendem a negar a ampla garantia de saúde.

Em relação ao SUS, o fato é que, por mais que se busque, com os recursos materiais disponíveis ao Estado, a satisfação do maior número de pessoas e realidades sociais, numa demonstração clara da concepção utilitarista de justiça social, a atenção voltada para a coletividade é, muitas vezes, inadequada, ao desconsiderar que as necessidades de saúde se manifestarão diferentemente em cada pessoa.

Portanto, na elaboração e realização de políticas públicas de saúde faz-se necessária uma interpretação ampliativa do conceito de saúde que considere o indivíduo destinatário do direito em todas as suas particularidades.

Ademais, a partir dessas características do direito à saúde e das normas que o instituem, não devem ser admitidos argumentos de cunho reducionista, quaisquer que sejam eles, nem os que negam o caráter de direito individual, pois embora sendo um direito social, a sua fruição se dá individualmente, tampouco os argumentos afetos à finitude de recursos, pois, como visto, os recursos, antes de serem finitos, são mal administrados.

É nesse sentido a teoria de justiça como equidade de Rawls, pois para ele cada indivíduo, e não somente a coletividade, é titular de um conjunto básico de direitos, todos indispensáveis para realização do plano de vida de qualquer pessoa. Esses bens correspondem aos direitos fundamentais, dentre eles os sociais constitucionalmente previstos, todos eles igualmente essenciais ao respeito e à promoção da dignidade e que devem, desse modo, serem garantidos pelo Estado, que está juridicamente obrigado a fazê-lo.

Assim, colocar qualquer restrição à prestação de saúde é colocar nas mãos do Estado decisão que não é sua, uma vez que o constituinte já decidiu. Não cabe ao Estado dizer quem atende e quem não atende, quem deve ter direito a um determinado tratamento e quem não deve, quais medicamentos atendem a maioria e quais não, e por isso não devem ser disponibilizados, pois decisões como estas acabam por prejudicar os menos favorecidos.

Ademais, só há realização do direito à saúde se as políticas públicas forem efetivas e os serviços forem prestados de forma plena, garantindo vida e dignidade aos indivíduos. Isso terá um custo, assim como a garantia de todos os direitos o tem. Porém, a arrecadação e gestão dos recursos orçamentários públicos são de responsabilidade do Estado que, portanto, e com base na correta eleição de prioridades, da garantia do direito a saúde não poderá se esquivar.

Por fim, pensar no Estado é pensar em um Ente que não tem um fim em si mesmo, mas está a serviço das pessoas. Logo, trata-se de um Ente que existe única e exclusivamente pela vontade da coletividade, do povo, verdadeiros titulares do Poder, e, portanto, sua função primeira se justifica na garantia de direitos tidos como essenciais pelo Legislador, como é o caso da saúde, direito social fundamental, assim considerado pelo Constituinte.

\section{REFERÊNCIAS}

BARCELlOS. Ana Paula de. A eficácia jurídica dos princípios constitucionais: O princípio da dignidade da pessoa humana. 3.ed.rev.atual. Rio de Janeiro: Renovar, 2011. 
BASTOS, Elísio Augusto Velloso. O Constitucionalismo Social. A Constituição como Instrumento Jurídico de Contenção do Poder Econômico. In Lições de Direito Constitucional em Homenagem ao Prof. Dr. Sérgio Resende de Barros. Campinas: Milennium Editora, 2007, p. 27-70.

BRASIL. Constituição da República Federativa do Brasil de 1988. Disponível em: $<$ http://www.planalto.gov.br/ccivil_03/constituicao/constituicao.htm>. Acesso em: 26 nov. 2016.

BRITO FILHO, José Claudio Monteiro de; FERREIRA, Vanessa Rocha. DIREITO FUNDAMENTAL À SAÚDE E TUTELA INDIVIDUAL: LENDO ESSE DIREITO CONSTITUCIONAL À LUZ DO LIBERALISMO IGUALITÁRIO. In: SILVEIRA, Vladmir Oliveira da. e CECATO, Maria Aurea Baroni (Org.). III Encontro de Internacionalização do CONPEDI (Madrid, Espanha): Direito Constitucional, Direitos Humanos. 1ed.Madrid España: Ediciones Laborum, 2015, v. 2, p. 274-290. Disponível em: <http://www.conpedi.org.br/wp-content/uploads/2016/03/Vol.-2-Madrid.pdf $>$. Acesso em 26 nov. 2016.

BRITO FILHO, José Claudio Monteiro de. Revista de Direito Internacional dos Direitos Humanos. Direito Fundamental à Saúde: Propondo uma concepção que reconheça o indivíduo como seu destinatário, v.2, n.1, p. 168- 182, jan./jun., 2014. Publicado também na Revista A Leitura/Caderno da Escola Superior da Magistratura do Estado do Pará, Vol. 5, n. 9 (nov. 2012), p. 136-145. Belém: ESM/PA, 2012.

Direitos Humanos. São Paulo: LTr, 2015.

BUCCI, Maria Paula Dallari. O conceito de política pública em direito. In: BUCCI, Maria Paula Dallari (Org.). Políticas públicas - reflexões sobre o conceito jurídico. São Paulo: Saraiva, 2006.

DIAS, Jean Carlos. O controle judicial de políticas públicas. São Paulo: Método, 2007.

DUARTE, Clarisse Seixas. O ciclo das políticas públicas. In: SMANIO, Gianpaolo Poggio. BERTOLIN, Patrícia Tuma Martins. O Direito e as Políticas Públicas no Brasil. São Paulo: Atlas, 2013, p. 16-43 (capítulo 2).

DWORKIN. Ronald. Levando os direitos à sério. Trad. Nelson Boeira. 1 ed. São Paulo: WMF Martins Fontes, 2002.

FLEISCHACKER, Samuel. Uma breve história da justiça distributiva. Tradução de Álvaro de Vita. São Paulo: Martins Fontes, 2006.

ORGANIZAÇÃO MUNDIAL DA SAÚDE. Constituição da Organização Mundial da Saúde (OMS/WHO). Nova Iorque, 1946. Disponível em: <http://www.direitoshumanos.usp.br/index.php/OMS-Organiza\%C3\%A7\%C3\%A3oMundial-da-Sa\%C3\%BAde/constituicao-da-organizacao-mundial-da-saude-omswho.html> Acesso em: 5 jun. 2016. 
PAES, Carolina Bastos Lima. O LIBERALISMO DE PRINCÍPIOS APLICADO À JUDICIALIZAÇÃO DOS DIREITOS SOCIAIS FUNDAMENTAIS: UMA PROPOSTA PARA A SUPERAÇÃO DE LIMITES DE ATUAÇÃO DO PODER JUDICIÁRIO. Belém, dissertação de mestrado, Programa de Pós- Graduação em Direito da Universidade Federal do Pará - UFPA, 2015.

PEREIRA, Leonardo Fadul. IGUALDADE FORMAL E SEGURANÇA JURÍDICA NAS DECISÕES JUDICIAIS EM AÇÕES COLETIVAS PARA FORNECIMENTO DE MEDICAMENTOS: UM ESTUDO DE CASOS DA SEÇÃO JUDICIÁRIA FEDERAL DO ESTADO DO PARÁ. Belém, dissertação de mestrado, Programa de Pós- Graduação em Direito, Políticas Públicas e Desenvolvimento Regional do Centro Universitário do Pará CESUPA, 2014.

PRATA, Lucília Alcione. Um Novo Locus de Formação das Políticas Públicas de Saúde: o Diagnóstico da Saúde pela Política Judiciária do Conselho Nacional de Justiça. In: SMANIO, Gianpaolo Poggio. BERTOLIN, Patrícia Tuma Martins. O Direito e as Políticas Públicas no Brasil. São Paulo: Atlas, 2013, p. 45-62 (capítulo 3).

RAWLS, John. Uma teoria da justiça. 4 ed.rev. Tradução de Jussara Simões. São Paulo: Martins Fontes, 2016.

SARLET, Ingo Wolfgang; FIGUEIREDO, Mariana Filchtiner. Algumas considerações sobre o direito fundamental à proteção e promoção da saúde aos 20 anos da Constituição Federal de 1988. Revista de Direito do Consumidor. São Paulo, n. 67, p. 125-172, 2008.

SARLET, Ingo Wolfgang. A titularidade simultaneamente individual e transindividual dos direitos sociais analisada à luz do exemplo do direito à proteção e promoção da saúde. In: NOBRE, Milton Augusto de Brito; SILVA, Ricardo Augusto Dias da (Coord.). O CNJ e os desafios da efetivação do direito à saúde. Belo Horizonte: Fórum, 2011. p. 117-147.

A eficácia dos direitos fundamentais: uma teoria geral dos direitos fundamentais na perspectiva constitucional. 12 ed. rev. atual e amp. Porto Alegre: Livraria do Advogado, 2015.

SCAFF, Fernando Facury. A efetivação dos direitos sociais no Brasil: garantias constitucionais de financiamento e judicialização. In SCAFF, Fernando Facury, ROMBOLI, Roberto, e REVENGA, Miguel (Coord.). A eficácia dos direitos sociais. São Paulo: Quartier Latin, p. 21-42, 2010.

SEN, Amartya. Desenvolvimento como liberdade. São Paulo: Companhia das Letras, 2000.

SUNSTEIN, Cass; HOLMES, Stephen. El Costo de Los Derechos: Por qué la libertad depende de los impuestos. Buenos Aires: Siglo Veintiuno Editores, 2011.

SMANIO, Gianpaolo Poggio. Legitimidade Jurídica das Políticas Públicas: A Efetivação da Cidadania. In: SMANIO, Gianpaolo Poggio. BERTOLIN, Patrícia Tuma Martins. O Direito e as Políticas Públicas no Brasil. São Paulo: Atlas, 2013, p. 3-15 (capítulo 1). 
VASCONCELOS, Cipriano Maria de; PASCHE, Dário Frederico. O sistema único de saúde. In: CAMPOS, Gastão Wagner de Souza; MINAYO, Maria Cecília de Souza; AKERMAN, Marco; JÚNIOR, Marcos Drumond; CARVALHO, Yara Maria de (Org.). Tratado de Saúde Coletiva. 2 ed. São Paulo: Hicitec, 2012.

VITA, Álvaro de. A justiça igualitária e seus críticos. $2^{\mathrm{a}}$ ed. São Paulo: WMF Martins Fontes, 2007.

KYMLICKA, Will. Filosofia política contemporânea: uma introdução. Tradução de Luís Carlos Borges. São Paulo: Martins Fontes, 2006. 